Authors' Contribution:

A Study Design

B Data Collection

C Statistical Analysis

D Data Interpretation

E Manuscript Preparation

$\mathbf{F}$ Literature Search

G Funds Collection

\section{The construction and empirical verification of the Sense of Team Efficacy Questionnaire}

\author{
(Kwestionariusz Poczucia Druzynowej Skutecznosci)
}

\author{
Zuzanna Walach-Bista \\ Department of Social and Environmental Sociology, \\ University of Silesia, Katowice, Poland
}

\title{
abstract
}

Background: This article presents the procedure of the elaboration and verification of the first Polish Sense of Team Efficacy Questionnaire (Kwestionariusz Poczucia Druzynowej Skutecznosci - KPDS).

Material/Methods:

Two research stages involved a total of 373 professional athletes. Based on the collected data, the internal structure and psychometric properties of the instrument were established.

Results: As a result of the conducted statistical analyses, a questionnaire was obtained. Analyses confirmed the stability of the internal structure of the questionnaire. The instrument also obtained satisfactory coefficients of reliability (using Cronbach's alpha internal reliability coefficient) and construct validity. In order to establish the convergent and discriminant validity of the KPDS, the analysis of the multitrait-multimethod matrix was applied, using the Group Environment Questionnaire (GEQ). Predictive validity was established using the result obtained in a match played directly after the conducted study.

Conclusions: The obtained results confirmed the relevance of creating the KPDS. The questionnaire was made up of 21 items representing 4 subscales: fitness, preparation, effort and endurance. Calculation of a general score for the KPDS also proved to be possible.

Key words: collective efficacy, measurement, sport psychology.

\section{article details}

Article statistics:

Full-text PDF:

Copyright

Indexation:

Conflict of interests: Corresponding author:

Open Access License:

Word count: 5743; Tables: 4; Figures: 0; References: 31

Received: June 2014; Accepted: January 2015; Published: March 2015

http://www.balticsportscience.com

Gdansk University of Physical Education and Sport

Celdes, CNKI Scholar (China National Knowledge Infrastructure), CNPIEC, De Gruyter - IBR (Internationa Bibliography of Reviews of Scholarly Literature in the Humanities and Social Sciences), De Gruyter - IBZ (International Bibliography of Periodical Literature in the Humanities and Social Sciences), DOAJ, EBSCO - Central \& Eastern European Academic Source, EBSCO - SPORTDiscus, EBSCO Discovery Service, Google Scholar, Index Copernicus, J-Gate, Naviga (Softweco, Primo Central (ExLibris), ProQuest - Family Health, ProQuest - Health \& Medical Complete, ProQuest - Illustrata: Health Sciences, ProQuest - Nursing \& Allied Health Source, Summon (Serials Solutions/ProQuest, TDOne (TDNet), Ulrich's Periodicals Directory/ulrichsweb, WorldCat (OCLC)

Author's own sources. No external funding was received.

Author has declared that no competing interest exists.

Zuzanna Walach-Bista, Dep. of Social and Environmental Sociology, University of Silesia, Grazynskiego 53 St. 40 Katowice, Poland; phone: +48 502297140; e-mail: zuzanna.walach@us.edu.pl

This is an open access article distributed under the terms of the Creative Commons Attribution-Non-commercial 4.0 International (http://creativecommons.org/licenses/by-nc/4.0/), which permits use, distribution, and reproduction in any medium, provided the original work is properly cited, the use is non-commercial and is otherwise in compliance with the license. 


\section{INTRODUCTION}

The notion of self-efficacy occupies a central position in Bandura's theory of social learning. Bandura [1] defined it as an individual's conviction that he or she would be able to behave in a way necessary to reach the planned goals. Specifically, the sense of self-efficacy is the individual's belief in him or herself, his or her potential and capabilities substantial for the desired and efficacious realization of a given task, regardless of the circum stances he or she is in [2]. The strength of the conviction of self-efficacy determines whether an individual even decides to take action. Consequently, it influences the choice of tasks by the individual, but also the amount of effort invested in performance of the task and the endurance in the face of the emerging obstacles [2].

Nevertheless, humans don't live in isolation. Many activities require taking autonomous action, but at the same time, individuals are also members of many groups or teams. That is why, in many situations people have to cooperate with one another in order to attain the things that they are not able to achieve by themselves. Therefore, an individual appraises not only his or her own potential, but also forms certain convictions concerning the efficacy of the whole group to which he or she belongs. Thus, Bandura extended his concept to the notion of the sense of collective efficacy (in sports often referred to as team efficacy).

Collective efficacy is a "group's shared belief in its conjoint capability to organize and execute the courses of action required to produce given levels of attainment" [2, p. 477].

Collective efficacy is not a simple sum of its members' self-efficacies [3]. What is particularly important here is the interaction and coordination of group members. That is why it is considered that the essence of the sense of collective efficacy was most fully formulated in the definition by Zaccaro et al. [4]. They described it as "a sense of collective competence shared among individuals when allocating, coordinating, and integrating their resources in a successful concerted response to specific situational demands" (p. 309).

The consequences of the sense of collective efficacy are similar to the consequences resulting from the sense of self-efficacy, but they extend to the level of the whole group. The higher the sense of collective efficacy, the greater the motivation of the whole team. At the same time, the endurance of the team in the face of approaching defeats rises, and that translates into a higher level of achieved results [2]. A meta-analysis of studies unquestionably demonstrated that a higher sense of collective efficacy leads to higher results achieved by the whole team [5]. It influences whether teams initiate action, and also the period of time in which the group effort will be sustained [6]. The results of the studies conducted on sports teams showed that the groups which are positive that they will achieve success put in more effort and display more endurance in the face of challenges and defeats than the teams who are not so certain [7, 8]. Moreover, the groups exhibiting this conviction put more effort in pursuing a goal than the units with equivalent skills but a low sense of team efficacy [9] and they are less prone to social loafing [10]. The sense of team efficacy also 
influences the goals selected for the whole team by the individual members [11]. As a result, a sense of team efficacy is an important predictor of team performance $[12,13]$ and players' satisfaction [14].

In accordance with Bandura's [2] approach, the development of the concept of the sense of team efficacy in sport is possible if appropriate instruments are employed in research. Therefore, Bandura compiled a guide for constructing self and collective efficacy scales [3]. Unfortunately, as for the present, no questionnaire measuring the sense of team efficacy in sports has been developed in Poland. For that reason, as an answer to the growing need for conducting research concerning the dynamics of sports teams and their functioning in Polish realities, a decision was made to create a questionnaire instrument to measure that variable. It is designed to be closely adapted to the conditions and realities of sports, universal enough, however, so that it may be applied among athletes practicing different team sports. The inspiration for the creation of the Sense of Team Efficacy Questionnaire (Kwestionariusz Poczucia Druzynowej Skutecznosci - KPDS) was the Collec-tive Efficacy Questionnaire for Sports by Short, Sullivan and Feltz [15]. The KPDS is an instrument that can be used to study Polish athletes practicing team sports. This article presents the process of developing the Sense of Team Efficacy Questionnaire along with the results of its psychometric elaboration.

\section{STUDY 1}

The aim of the first study was to prepare the first, preliminary version of the questionnaire measuring the sense of team efficacy in sports. As a result of the conducted analyses, an initial pool of questionnaire items was created. Subsequently, male and female team sports athletes were tested using these items. The conducted statistical analyses were to provide information concerning the psychometric properties of the preliminary version of the questionnaire measuring the sense of team efficacy. Thus, the aim of the study was to determine the internal structure of the newly prepared questionnaire and its content validity as well as to establish the reliability of both the subscales that were isolated and the entire instrument.

\section{MATERIAL AND METHODS}

\section{STUDY GROUP}

The study concerning the preliminary version of the questionnaire measuring team efficacy was conducted on a group of 200 professional team sports athletes who were members of Silesian sports clubs. Men constituted $66 \%$ of the study group. All the respondents took part in league competitions: the majority were players of the 2 nd league $(42.9 \%)$, but there were also premier league (9.1\%), 1 st (20.7\%) and 3rd (27.3\%) league players. More than half of the participants (58.5\%) were football players, and women constituted almost $22 \%$ of that group. $22 \%$ of the respondents were women playing volleyball at the level of the 2 nd and the 3rd league. The study group also encompassed basketball (5\%), futsal (5.5\%) and handball (9\%) players. In total, 13 sports teams were studied. The age of the participants ranged from 15 to 38 years $(M=20.98$; $\mathrm{SD}=5.71$ ). On average, the respondents had been training the chosen sport for more than 10 years, but the study group also encompassed persons who 
had been training for one year and those who had been training for over 30 years $(M=10.5 ; \mathrm{SD}=5.93)$. Generally, the athletes had been members of their current teams for 2 years $(\mathrm{M}=2.92 ; \mathrm{SD}=2.77$; $\min =0.2$; $\max =18)$.

\section{Procedure}

The study was conducted in the duration of the 2013/2014 regular season. The collection of data was commenced in October 2013, when all the teams had played at least two games in the regular season. After a prior telephone contact with the coaches of the teams, the researcher came to the practice in person, and, depending on the determinations, the study was conducted before or after finishing the practice. The respondents received the Sense of Team Efficacy Questionnaire (KPDS-41) and a demographics sheet containing questions concerning the trained sport, age, the duration (in years) of practicing the trained sport and the duration (in years) of being a member of the current team. All the questionnaires were collected by the researcher personally, so as to retain full anonymity of the participants, and also in order to give the athletes the certainty that the coaching staff would not access the answers given by them.

\section{The Sense of Team Efficacy Questionnaire (KPDS-33)}

The first step in constructing the question-naire was a detailed review of the literature concerning the sense of self-efficacy and the sense of collective efficacy [2]. The process of constructing the questionnaire was based on Bandura's guidelines concerning creating new scales dealing with the sense of efficacy [3].

Questionnaire items referring to efficacy should accurately reflect the meaning of this construct. Both the sense of self-efficacy and of collective efficacy are tied to the perception of one's own and the team's capabilities. For that reason, the questionnaire items should be constructed in terms of I can/ we can, and not in terms of I will do/we will. I can/we can is an appraisal of one's own or the team's capabilities, whereas I will/we will is the statement of our intention [3]. All the items that were included in the KPDS-33 satisfied that assumption.

The creation of the initial pool of items that were to make up the Sense of Team Efficacy Questionnaire was based on a number of sources. First, the definition of the sense of collective efficacy by Bandura [2] and Zaccaro, Blair, Peterson and Zazanis [4] was considered, as well as the sources and results of this construct. Afterwards, the methods used in the measurement of collective efficacy were reviewed, focusing particularly on the Collective Efficacy Questionnaire for Sports [15]. A translation of the items included in the CEQS scale by Short et al. [15] was prepared and incorporated in the initial pool of items which were to make up the KPDS. A pilot study was also conducted, in which team sports athletes were asked to list situations which caused them difficulties, as a team, to beat their opponents during the games played. Based on the identified challenges and obstacles, further items making up the sense of team efficacy were created. As a result of that, a pool of 41 questionnaire items was created, which were to make up the Sense of Team Efficacy Questionnaire, code named KPDS-41. 
There are two approaches to studying the sense of group efficacy. In the first approach, individual assessments of respective group members' personal capabilities to perform specific roles in the group are summed up. The second approach assumes summing up the assessments of the respective group members concerning the ability of their group functioning as a whole. The latter approach assumes a comprehensive assessment, encompassing also aspects concerning the co-ordination and integration which take place in a group. That is the reason why Bandura [3] suggests that the first approach will work very well especially in the study of teams in which the interdependent effort necessary to obtain the desired result is low, like for example in a team of swimmers. On the other hand, the second approach will be more effective when studying teams where the interdependence of the players is very high (like football, volleyball, basketball, etc.). For that reason, the instruction for the players studied by the KPDS was formulated in the following way: „Rate the confidence of your team, in terms of the upcoming game, that it has the sufficient capabilities to:". The respondents note the strength of their team's convictions concerning its efficacy on a 10-point scale, with 1-unit steps, where 0 means "not certain at all", and 10: "exceptionally certain". This is coherent with Bandura's [3] guidelines, suggesting that the scales for measuring the sense of efficacy should be in the grade range from 0 to 100 , or, in a more simple version, from 0 to 10 , because such scales are characterized by a higher reliability that less complex ones.

The instrument obtained this way, codenamed KPDR-41, was verified for content validity. On a four-grade scale, competent judges $(n=10)$ rated the compatibility of the statements and the degree of their representativeness with the definition of the sense of team efficacy in sports. For each item, a content validity ratio (CVR) was calculated [16]. After eliminating the items with a CVR index lower than the minimum value of 0.62 , the content validity of the entire questionnaire was estimated. The content validity index (CVI) of the entire instrument was 0.87. An analysis of the index of discrimination power of test items was also conducted. The items with the discrimination power index of rbi $>0.50$ were qualified for further analyses. As a result of preliminary analyses, 33 questionnaire items were isolated, making up the KPDR-33, which was subjected to further statisti-cal analyses in order to verify its internal structure.

\section{RESULTS}

Factor structure of the KPDS-33 questionnaire. In order to determine the internal structure of the first version of the KPDS-33, the set of isolated items was subjected to a procedure of exploratory factor analysis. The factor analysis was preceded by conducting the Bartlett's test of sphericity $\left(x^{2}=5209.11\right.$; $\mathrm{df}=190 ; \mathrm{p}<0.01)$ and testing the KMO measure of sampling adequacy (0.936), which confirmed the relevance of hypothesizing the existence of a factor structure of the questionnaire [17]. In the analysis, principal component analysis (PCA) with Promax rotation was applied. Oblique rotation was selected based on the study results obtained by Short, Sullivan and Feltz [15] concerning the Collective Efficacy Questionnaire for Sports, which demonstrated that the subscales of the sense of team efficacy are correlated with each other. Moreover, Bandura [3] himself claimed that the statements reflecting the notion of the sense of team efficacy should be correlated both with each other and with the general score. 
As a result of conducting the exploratory factor analysis by means of principal component analysis (PCA) with Promax rotation, 5 main components were obtained, in accordance with the Kaiser criterion [18], with own value greater than one (16.73, 2.61, 1.66, 1.21 and 1.07, respectively), jointly explaining $70.56 \%$ of the variance. However, based on the analysis of the scree plot, a decision was reached to adopt a four-factor solution, which jointly explained $67.31 \%$ of the variance. The contribution of the individual factors was: $14.50 \%$, $10.12 \%, 12.14 \%$ and $9.40 \%$, respectively.

In the next stage, the items making up the KPDS-33 were subjected to reduction. When reducing the questionnaire items, both statistical and conceptual approaches were employed. Table 1 presents factor loadings included in the model matrix. In the selection of items subjected to subsequent analyses, the following criteria were used: 1 ) the factor loading should reach a value of at least 0.45 for one factor and 2) the value of the factor loading on the remaining factors should not be greater than 0.40 . Furthermore, the analysis of the structural matrix demonstrated that the correlation of the individual variables with the respective factors [17] ranged from 0.62 to 0.90 . This is indicative of a good fit of the items to the factors.

The content analysis and interpretation of items with factor loadings reaching the appropriate values led to the isolation of factors that were named: Endurance, Effort, Fitness and Preparation. These names were chosen due to their consistency with the notion of the sense of efficacy by Bandura [3]. They are also compatible with the factors isolated in the questionnaire measuring the sense of team efficacy: Collective Efficacy Questionnaire for Sports [15].

In the next step, the 29 questionnaire statements with factor loadings reaching the value of over 0.45 for one factor were again subjected to content verification. The competent judges $(n=10)$ rated the content validity of respective statements on a four-grade scale. This time, they rated the compatibility degree of the item and the isolated factor. Based on the ratings of the competent judges, for each questionnaire item a content validity ratio (CVR) was calculated for the isolated subscale. In accordance with the recommendations of Lawshe [16], the items with content validity indices not reaching the minimum value of 0.62 were eliminated from the final version of the questionnaire. Subsequently, in order to assess the content validity of the entire questionnaire, the content validity index (CVI) was calculated for the whole instrument. The CVI value is a mean of the content validity of each item that reached the minimum acceptable CVR. In the Sense of Team Efficacy Questionnaire it amounted to 0.86 . As a result of the conducted procedures, 21 questionnaire items fulfilling the required and previously established criteria were isolated. The Preparation subscale was made up of 4 items; Fitness of 5 items; Effort of 6 items and the Endurance subscale also consisted of 6 items.

In a subsequent analysis, the isolated 21 questionnaire items were again subjected to exploratory factor analysis using the principal components method with Promax rotation, in order to reverify the internal structure of the questionnaire elaborated in this way. Bartlett's test of sphericity $\left(x^{2}=2931.46\right.$; $\mathrm{df}=210, \mathrm{p}<0.000)$ and the KMO index (0.929) confirmed the relevance of con-ducting the factor analysis. Based on the Kaiser criterion and the scree plot, it was again established that the four-factor solution was the most re- 
levant one. The four main components jointly explained $71.1 \%$ of the variance, whereas the rotation sums of squared loadings amounted to: for the first factor - 8.57; for the second one - 7.41; for the third one -7.87 and for the fourth one -6.10 . All subscales were moderately and strongly correlated both with each other and with the general result of the KPDS questionnaire (from 0.52 to $0.89 ; \mathrm{p}<0.01$ ).

The analysis of the diagonal of the anti-image correlation matrix, presenting the individual values of the KMO measure for each respective questionnaire item, demonstrated that a 21-item questionnaire fulfils the requirements of the KMO measure with respect to each item separately [19]. The measures of sampling adequacy for the respective items ranged from 0.856 to 0.962 . In turn, the analysis of the replicated correlation matrix demonstrated the existence of $58(27 \%)$ non-redundant residuals with absolute values greater than 0.05 .

The factor loadings for the respective items from the four subscales after the rotation reached acceptable values in the range from 0.53 to 0.95 . For each item, the factor loading reached the highest value on the same factor, as was the case when the first exploratory factor analysis was conducted.

\section{RELIABILITY ANALYSIS}

In the subsequent step, the subscales isolated using exploratory factor analysis were subjected to a reliability analysis. This was done based on the ratings of the Cronbach's alpha internal consistency coefficients, which were calculated both separately for each of the isolated subscales and for the general score. All the subscales of the questionnaire demonstrated satisfacto-ry reliability coefficients: for the Fitness subscale $=0.87$; Preparation $=0.90$; Effort $=0.88$; Endurance $=0.91$; and for the general score $=0.95$. The item - scale correlations for the Fitness factor ranged from 0.60 to 0.78 , for the Preparation factor from 0.66 to 0.87 , for the Effort factor from 0.63 to 0.75 and for the Endurance factor from .71 to .79 . Whereas the item-general score correla-tions ranged from .57 to .78 .

Table 1. Factor loadings for the respective test items.

\begin{tabular}{lllll} 
& & & & \\
& FACTOR & & \\
\hline & $(F 1)$ & $(F 2)$ & $(F 3)$ & $(F 4)$ \\
\hline Resolve conflicts & $0.94^{*}$ & -0.10 & 0.08 & -0.06 \\
\hline Resolve problems in a spirit of cooperation & $0.97^{*}$ & -0.14 & 0.16 & -0.11 \\
\hline Be united & $0.80^{*}$ & 0.00 & 0.16 & -0.10 \\
\hline Maintain a positive attitude & $0.71^{*}$ & 0.22 & 0.05 & -0.11 \\
\hline Keep calm under pressure & $0.65^{*}$ & 0.20 & -0.10 & 0.04 \\
\hline Cooperate & $0.80^{*}$ & 0.05 & 0.09 & -0.04 \\
\hline Maintain control during the whole game & $0.70^{*}$ & 0.10 & 0.03 & -0.02 \\
\hline Effectively communicate during the game & $0.63^{*}$ & 0.11 & 0.05 & 0.14 \\
\hline Regain the lead to achieve success & $0.49^{*}$ & 0.30 & -0.12 & 0.15 \\
\hline Get up and regain the lead after playing poorly & $0.65^{*}$ & 0.17 & -0.22 & 0.15 \\
\hline Notice weak points of its opponents & $0.73^{*}$ & -0.24 & -0.13 & 0.29 \\
\hline Work together as a team & 0.54 & 0.45 & 0.02 & -0.15 \\
\hline Set goals & 0.44 & -0.09 & 0.03 & 0.40 \\
\hline Exhibit more determination than the opposing team & 0.36 & 0.09 & 0.31 & 0.22 \\
\hline
\end{tabular}




\begin{tabular}{lllll}
\hline Work hard as a team & 0.11 & $0.72^{*}$ & 0.09 & -0.08 \\
\hline Put in maximum effort & -0.20 & $0.98^{*}$ & -0.14 & 0.16 \\
\hline Demonstrate strong work ethic & -0.03 & $0.89^{*}$ & 0.03 & -0.09 \\
\hline Maintain motivation & 0.08 & $0.79^{*}$ & 0.12 & -0.14 \\
\hline Maintain concentration & 0.27 & $0.63^{*}$ & 0.02 & -0.12 \\
\hline Play as good as possible & 0.03 & $0.46^{*}$ & 0.30 & 0.10 \\
\hline Maintain the commitment to achieving goals & 0.24 & $0.47^{*}$ & -0.04 & 0.24 \\
\hline Display more ability than the opposing team & -0.20 & 0.02 & $0.54^{*}$ & 0.40 \\
\hline Outplay the opposing team & 0.03 & -0.09 & $0.90 *$ & 0.01 \\
\hline Win in this game & 0.04 & -0.04 & $0.92^{*}$ & -0.08 \\
\hline Achieve success & 0.05 & -0.03 & $0.83^{*}$ & 0.05 \\
\hline Demonstrate a greater resilience than the opposing team & 0.01 & 0.15 & $0.68^{*}$ & -0.08 \\
\hline Demonstrate a strong foundation & 0.32 & -0.11 & $0.48^{*}$ & 0.20 \\
\hline Reach its goals & 0.02 & 0.27 & $0.47^{*}$ & 0.13 \\
\hline Demonstrate physical fitness & -0.19 & 0.10 & 0.39 & $0.55^{*}$ \\
\hline Physically prepare for this game & -0.07 & -0.04 & 0.08 & $0.91^{*}$ \\
\hline Be adequately prepared for this game & -0.03 & -0.04 & 0.14 & $0.86^{*}$ \\
\hline Mentally prepare for this game & 0.31 & -0.06 & -0.09 & $0.72^{*}$ \\
\hline Adapt to various situations & 0.43 & 0.24 & -0.27 & 0.45 \\
\hline $\mathrm{n}=200 ; *(>0.45$ and < 0.40) & & & &
\end{tabular}

\section{STUDY 2}

The aim of the second study was to re-verify the internal structure of the KPDS-21 questionnaire, which was created as a result of the statistical analyses conducted in the first study, in order to demonstrate the stability and reproducibility of the factor structure of the newly created instrument. To this end, the EFA was again conducted. Moreover, statistical analyses were per-formed in order to provide additional evidence for the reliability of both the individual subscales and the entire instrument. The criterion validity was verified, in which the criterion for the new questionnaire was the result of the team achieved in a game played directly after the study. In order to additionally confirm that the KPDS-21 is an instrument characterized by high construct validity, it was verified for convergent and discriminant validity. A systematic analysis of factor loadings was conducted according to the criteria set out by Helmes [20], as well as a multitrait-multimethod matrix analysis [16].

Both the general framework for examining the correlates of group cohesion in sports $[21,22]$ and the conceptual model of the sense of team efficacy [23, 24 ] assume that group cohesion and the sense of team efficacy are interrelated. Empirical research in sports also confirmed the relations of these two constructs. Among others, Spink [25] demonstrated that in volleyball teams with a high sense of team efficacy, the members highly assessed their individual attractions to the team-task and group integration-social at the same time. Similar results were obtained by Paskevich, Brawley, Dorsch and Widmeyer [26] as well as by Kozub and McDonnell [27], who demonstrated the existence of a positive relation of the sense of team efficacy and the group integration-task as well as individual attractions to the team-task, which reflect the dimension of task group cohesion in sports. On the other hand, in their research Heuze, Bosselut and Thomas [28] only obtained a confirmation of the fact that the sense of team efficacy is a significant predictor exclusive of 
individual attractions to the team task. More contemporary studies supply a downright confirmation that the sense of team efficacy is a mediator of the dependence between individual performance of an ath-lete and the group integration task [29].

Based on the above data, it was considered reasonable to conduct a measurement using an instrument for the measurement of group cohesion in order to demonstrate the convergent and dis-criminant validity. An identical procedure was also carried out during the process of creation of the Collective Efficacy Questionnaire for Sports [15]. It was assumed that the correlations between the subscales of the Sense of Team Efficacy Questionnaire would be higher than the correlations be-tween the subscales of the KPDS and the subscales of the questionnaire measuring group cohe-sion. It was also considered that the highest correlation would occur between the sense of team efficacy and task group cohesion, with particular emphasis on the group integration task. As the current research demonstrated that there are no grounds to assume a high correlation of the sense of team efficacy and the social dimensions of group cohesion, it was considered that the correlation between these variables should be substantially lower.

\section{MATERIAL AND METHODS}

Study group. The second stage of the research encompassed 173 athletes (men constituted $69 \%$ of that group) practicing football (30.6\%), volleyball (32.9\%), basketball (9.8\%) and hockey (26.6\%). A vast majority of the respondents (61.8\%) was made up of players of the 2 nd league. The mean age was $\mathrm{M}=20.39(\mathrm{SD}=3.63 ; \min =15 ; \max =34)$. In turn, the mean duration of training a given sport was $\mathrm{M}=10.29(\mathrm{SD}=3.88$; $\min =1.5 ; \max =26)$.

\section{Procedure}

Like Study 1, this study was also conducted in the period of the 2013/2014 regular season. The collection of the questionnaires was commenced roughly about the middle of the competitions, and it was completed before the start of the play-offs. After a prior telephone contact, the researcher came in person before or after the practice. The athletes received sets of questionnaires containing: a demographics sheet (with the same questions as in Study 1), the Sense of Team Efficacy Questionnaire (KPDS) and the Kwestionariusz Srodowiska Grupowego (Group Environment Questionnaire; [30] Polish version: [31]). Like in Study 1, the research procedure was organized in such a way as to ensure full anonymity of the athletes taking part in Study 2 .

Kwestionariusz Srodowiska Grupowego (GEQ). The Kwestionariusz Srodowiska Grupowego is a Polish adaptation of the Group Environment Questionnaire [30]. It serves the measurement of the perception of group cohesion. It is based on a conceptual model of group cohesion in sports. It is made up of 18 items, which constitute four subscales: a) individual attraction to the group-task (ATGT), b) individual attraction to the group-social (ATGS), c) group integration-task (GIT) and d) group integration-social (GIS). The GEQ distinguishes two dimensions: the task vs. social aspect, and individual vs. group orientation. The term group integration means the individual feelings of team members relating to similarity, closeness and bonds with the group understood as a social unit or as a whole joined by a common task. Individual 
attraction to the group, in turn, reflects the feeling of the team members concerning their personal engagement in the group goal or in social interactions with the group [31]. The respondents rate questionnaire items on a 9-point scale (from "I don't agree at all" to "I fully agree"). The reliability for all subscales calculated using the Cronbach's alpha coefficient in the aforementioned study was satisfactory (see Table 2).

\section{RESULTS}

Internal structure of the KPDS. In order to verify the stability of the internal structure of the questionnaire, a procedure identical to the one applied in Study 1 was employed. An EFA was conducted by means of principal component analysis with Promax rotation. Bartlett's test of sphericity proved to be significant $\left(\mathrm{x}^{2}=2785.99 ; \mathrm{df}=210 ; \mathrm{p}<0.01\right)$, and the value of the KMO measure was satisfactory (0.921). The four-factor solution jointly explained $71.77 \%$ of the variance. This result is consistent with the results of the first study. The rotation sums of squared loadings amounted to 7.65 for the Fitness subscale, 7.17 for the Preparation subscale, 4.69 for the Effort subscale and 9.60 for the Endurance subscale. All subscales were moderately and strongly correlated both with each other and with the general result of the KPDS questionnaire (see Table 2). Factor loadings for individual items from the four subscales after oblique rotation reached acceptable values within the range from 0.47 to 0.98 . For the Fitness subscale the factor loadings ranged from 0.47 to 0.94 , for the Preparation subscale: $0.48-0.98$, for the Effort subscale: $0.57-0.86$, and for the Endurance subscale: $0.47-0.98$.

Based on the analysis of the structural matrix, the correlations of the individual variables with the respective factors were established, which ranged from 0.48 to 0.94 . The analysis of the diagonal of the anti-image correlation matrix has once more demonstrated that the 21-item questionnaire fulfils the requirements of the KMO measure in relation to each item separately (from 0.87 to 0.96 ). The analysis of data contained in the replicated correlation matrix, in turn, demonstrated the existence of 53 (25\%) non-redundant residuals with absolute values higher than 0.05 . These results of the analyses of the final version of the KPDS in the second study group confirmed the cohesion of the internal structure of the questionnaire.

Analysis of convergent and discriminant validity. The systematic analysis of factor loadings isolated by means of the EFA with Promax rotation was conducted according to the criteria set out by Helmes and allowed for the consideration of the convergent and discriminant validity of the isolated subscales of the Sense of Team Efficacy Questionnaire [20]. All the indices of the convergent and discriminant validity for each subscale assumed maximal value, which indicates a high validity of the KPDS questionnaire.

Furthermore, the correlations between the subscales of the Sense of Team Efficacy Questionnaire (KPDS) and the Kwestionariusz Srodowiska Grupowego (GEQ) were analysed. The obtained indices were presented in Table 2. The intercorrelations of the KPDS subscales and the general scores ranged from 0.45 to $0.91(\mathrm{p}<0.01)$. The correlations between the KPDS and the GEQ were also significant, but decidedly lower - they ranged from 0.18 to 0.40 . The obtained results confirmed a high convergent and discriminant validity of the KPDS. Higher correlations were obtained among the subscales of the 
KPDS and the task dimension of group cohesion (GIT and ATGT), which conforms to the assumed hypotheses.

Table 2. Correlations between the subscales of the Sense of Team Efficacy Questionnaire (KPDS) and the Kwestionariusz Srodowiska Grupowego (GEQ) and reliability (on the diagonal).

\begin{tabular}{llllllllll} 
Subscales & 1 & 2 & 3 & 4 & 5 & 6 & 7 & 8 & 9 \\
\hline KPDS & & & & & & & & \\
\hline 1. Endurance & 0.90 & & & & & & & & \\
\hline 2. Fitness & $0.66^{* *}$ & 0.91 & & & & & & & \\
\hline 3. Effort & $0.73^{* *}$ & $0.58^{* *}$ & 0.87 & & & & & & \\
\hline 4. Preparation & $0.63^{* *}$ & $0.45^{* *}$ & $0.68^{* *}$ & 0.88 & & & & \\
\hline 5. General Score & $0.91^{* *}$ & $0.79^{* *}$ & $0.88^{* *}$ & $0.78^{* *}$ & 0.95 & & & \\
\hline GEQ & & & & & & & & \\
\hline 6. ATGT & $0.33^{* *}$ & $0.29^{* *}$ & $0.35^{* *}$ & $0.36^{* *}$ & $0.39^{* *}$ & 0.69 & & \\
\hline 7. ATGS & $0.30^{* *}$ & $0.23^{* *}$ & $0.28^{* *}$ & $0.28^{* *}$ & $0.32^{* *}$ & $0.47^{* *}$ & 0.72 & \\
\hline 8. GIT & $0.36^{* *}$ & $0.27^{* *}$ & $0.40^{* *}$ & $0.36^{* *}$ & $0.40^{* *}$ & $0.48^{* *}$ & $0.50^{* *}$ & 0.72 \\
\hline 9. GIS & $0.29^{* *}$ & $0.18^{*}$ & $0.27^{* *}$ & $0.22^{* *}$ & $0.29 * *$ & $0.41^{* *}$ & $0.53^{* *}$ & $0.60^{* *}$ & 0.84 \\
\hline
\end{tabular}

$\mathrm{n}=173 ; * \mathrm{p}<0.05 ; * * \mathrm{p}<0.01$

\section{Criterion VALIDITY}

For the purpose of analysing the predictive validity of the instrument described herein, a test of significance of differences was conducted. The criterion for the division of the study group into two separate groups was the result of the team achieved in a game played directly after the study (winning vs. losing). Table 3 presents the obtained results. In conformity with the assumed hypotheses, the players who won in a game played directly after the study, obtained high-er results in all subscales of the KPDS than the players who lost in the game played after the study. The obtained results conform to the conceptual model of the sense of team efficacy, which assumes that the sense of team efficacy has a direct influence on the effort and endurance during games, and, in consequence, the final outcome of the game [24].

Table 3. Differences in the assessment of the sense of team efficacy between teams winning a game directly after the study and teams losing a game.

\begin{tabular}{|c|c|c|c|c|c|c|}
\hline \multirow[t]{2}{*}{ Subscales } & \multicolumn{2}{|c|}{ Winners $(n=50)$} & \multicolumn{4}{|c|}{ Losers ( $n=76)$} \\
\hline & Mean rank & Rank-sum & Mean rank & Rank-sum & $\begin{array}{l}\text { U Mann-Whit- } \\
\text { ney }\end{array}$ & Z \\
\hline Endurance & 72.35 & 3617.50 & 57.68 & 4383.50 & 1457.50 & $-2.21 *$ \\
\hline Fitness & 78.48 & 3924.00 & 53.64 & 4077.00 & 1151.00 & $-3.74 * *$ \\
\hline Effort & 73.83 & 3691.00 & 56.71 & 4310.00 & 1384.00 & $-2.58 *$ \\
\hline Preparation & 74.10 & 3705.00 & 56.53 & 4296.00 & 1370.00 & $-2.65^{* *}$ \\
\hline General Score & 76.53 & 3826.50 & 54.93 & 4174.50 & 1248.50 & $-3.25^{* *}$ \\
\hline
\end{tabular}

Reliability analysis. The reassessment of the reliability of the Sense of Team Efficacy Questionnaire was conducted based on the Cronbach's alpha internal reliability coefficient. Table 3 presents the obtained results. Cronbach's alpha coefficients - both for all subscales and for the general result - reached values above 0.70 . This reliability values can be considered excellent [19]. Moreover, the item - scale correlations for the Fitness factor ranged from 
0.63 to 0.87 , for the Preparation factor from 0.58 to 0.86 , for the Effort factor from 0.57 to 0.75 and for the Endurance factor from 0.66 to 0.80 . The item general score correlations, in turn, ranged from 0.53 to 0.77 .

\section{DISCUSSION}

Statistical analyses conducted in the two research stages provide grounds to deem that the constructed instrument measuring the sense of team efficacy is a reliable and valid questionnaire, characterized by a stable internal structure. Overall, it is made up of 21 items reflecting four dimensions: effort, endurance, preparation and fitness.

The Effort subscale describes the conviction of the team members that their team is able to strive to reach the goals set for a given game, that the team is able to make every effort for that purpose. Endurance is the conviction of the team members that they are able to patiently and persistently pursue the realization of the set goals during games, and that they will not be quick to become discouraged by the emerging difficulties. Preparation is a dimension reflecting the conviction of the team members that their team will do everything to be appropriately prepared to upcoming games at a given moment. Fitness, in turn, is the assessment of the team concerning the degree in which it is able to demonstrate skills and capabilities thanks to which it will effectively fulfil the task that it was given during the games. All the subscales are strongly intercorrelated, which makes it possible to sum up all the results and calculate a general score representing the general index of the sense of team efficacy.

In the process of creating the questionnaire, Bandura's [3] guidelines included in his guide for constructing self-efficacy scales were taken into account. The Collective Efficacy Questionnaire for Sports [15] also had a strong influence on the final shape of the KPDS.

\section{CONCLUSION}

The Sense of Team Efficacy Questionnaire (KPDS) is an instrument that is closely adapted to the sports environment and can be applied to study the sense of team efficacy in various team sports. The validation of the instrument was conducted on a study group of players of team sports characterized by high interdependence of team members (football, handball, volleyball, basketball, hockey, futsal). Therefore, caution is required when using this instrument in other team sports where the interdependence of the team members is not as essential (such as team ski jump, swimming, rowing etc.). It would be advisable to establish the psychometric indices of the KPDS for such a purposive sample as well.

The constructed instrument can be applied both in research devoted to the issue of group processes and in the daily practice of sports psychologists and coaches. Conducting studies of Polish sports teams using the KPDS will allow for a better understanding of the essence of the sense of team efficacy in sports: gaining knowledge of the sources and outcomes of the team be-lief shaped in such a way. Such research will also enable the verification of the existing models of group processes [22, 24]. Coaches and psychologists, in turn, will be able to use this instrument to measure the sense of efficacy 
of their sports teams, plan and carry out interventions corresponding to the obtained results. Therefore, the KPDS may be an instrument assisting the detection of poten-tial problems and, consequently, facilitating the functioning of sports teams.

\section{REFERENCES}

[1] Bandura A. Teoria spolecznego uczenia sie [Social learning theory]. Warsaw: Wydawnictwo Naukowe PWN; 2007. Polish.

[2] Bandura A. Self-efficacy: The exercise of control. New York: Freeman; 1997.

[3] Bandura A. Guide for constructing self-efficacy scales. In: Pajares F, Urdan T, editors. Self-Efficacy Beliefs of Adolescents. Greenwich, CT: Information Age Publishing; 2006, 307-337.

[4] Zaccaro SJ, Blair V, Peterson C, Zazanis, M. Collective-efficacy. In: Maddux JE, editor. Self-efficacy, adaptation and adjustment: Theory, research and application. New York: Plenum; 1995, 308-330.

[5] Gully SM, Incalcaterra KA, Joshi A, Beaubien JM. A meta-analysis of team-efficacy, potency, and performance: Interdependence and level of analysis as moderators of observed relationships. J Appl Psy-chol. 2002;87:819-832.

[6] Stajkovic AD, Lee D, Nyberg AJ. Collective efficacy, group potency, and group performance: meta analyses of their relationship, and test of a mediation model. J Appl Psychol. 2009;94:814-828.

[7] Bray SR. Collective efficacy, group goals, and group performance of a muscular endurance task. Small Group Research. 2004;35:230-238.

[8] Hodges L, Carron A. Collective-efficacy and group performance. Int J Sport Psychol. 1992;23:48-59.

[9] Greenless IA, Graydon JK, Maynard IW. The impact of collective efficacy beliefs on effort and persistence in a group task. J Sport Sci. 1999;17:151-158.

[10] Lichacz FM, Partington JT. Collective-efficacy and true performance. Int J Sport Psychol. 1996;27:146158.

[11] Greenless IA, Graydon JK, Maynard IW. The impact of individual efficacy beliefs on group goal selection and group goal commitment. J Sport Sci. 2000;18:451-459.

[12] Myers ND, Feltz DL, Short SE. Collective-efficacy and team performance: A longitudinal study of collegiate football teams. Group Dynamics: Theory, Research and Practice. 2004;8:126-138.

[13] Myers ND, Payment CA, Feltz DL. Reciprocal relationships between collective efficacy and team performance in women's ice hockey. Group Dynamics: Theory, Research and Practice. 2004;8:182-195.

[14] Blecharz J, Luszczynska A, Scholz U, Schwarzer R, Siekanska M, Cieslak R. Predicting performance and performance satisfaction: mindfulness and beliefs about the ability to deal with social barriers in sport. Anxiety, Stress, And Coping. 2014;27:270-287.

[15] Short SE, Sullivan P, Feltz DL. Development and Preliminary Validation of the Collective Efficacy Questionnaire for Sport. Measurement in Physical Education and Exercise Science. 2005;9:181-202.

[16] Hornowska E. Testy psychologiczne. Teoria i praktyka [Psychological tests. Theory and practice]. Warsaw: Wydawnictwo Naukowe Scholar; 2013. Polish.

[17] Zakrzewska M. Analiza czynnikowa w budowaniu i sprawdzaniu modeli psychologicznych [Factor analysis in constructing and verifying psychological models]. Poznan: Wydawnictwo Naukowe Uniwersytetu Adama Mickiewicza; 1994. Polish.

[18] Wieczorkowska G, Wierzbinski J. Statystyka. Analiza badan społecznych [Statistics. Analysis of social research]. Warsaw: Wydawnictwo Naukowe Scholar; 2007. Polish.

[19] Bedynska S, Cypryanska M. Zaawansowane metody tworzenia wskaznikow - eksploracyjna analiza czynnikowa i testowanie rzetelnosci skali [Advanced methods of creating indices - exploratory factor analysis and testing the reliability of scales]. In: Bedynska S, Cypryanska M, editors. Statystyczny drogowskaz 1. Praktyczne wprowadzenie do wnioskowania statystycznego. Warsaw: Szkoła Wyzsza Psychologii Społecznej i Wydawnictwo Akademickie Sedno; 2013, 245-283. Polish.

[20] Brzozowski P. Skala uczuc pozytywnych i negatywnych SUPIN. Polska adaptacja skali PANAS Davida Watsona i Lee Anny Clark. Podrecznik. [SUPIN Scale of positive and negative feelings. Polish adaptation of David Watson's and Lee Ann Clark's PANAS scale. Textbook.]. Warsaw: Pracownia Testow Psychologicznych Polskiego Towarzystwa Psychologicznego; 2010. Polish.

[21] Carron AV. Cohesiveness in sport groups: Interpretations and Considerations. J Sport Psychol. 1982;4:123-138.

[22] Carron AV, Hausenblas HA, Eys MA. Group dynamics in sport (3rd ed.). Morgantown, WV: Fitness In-formation Technology; 2005.

[23] Beauchamp MR. Efficacy beliefs within relational and group contexts in sport. In: Jowett S, Lavallee D, editors. Social psychology in sport. Champaign, IL: Human Kinetics; 2007, 181-193.

[24] Beauchamp MR, Eys MA. Group dynamics in exercise and sport psychology: Contemporary themes. London/New York: Routledge Taylor \& Francis Group; 2008.

[25] Spink KS. Group cohesion and collective efficacy of volleyball teams. J Sport Exerc Psychol. 1990;12:301-311. 
[26] Paskevich DM, Brawley LR, Dorsch KD, Widmeyer WN. Relationship between collective efficacy and team cohesion: Conceptual and measurement issues. Group Dynamics: Theory, Research and Practice. 1999;3:210-222.

[27] Kozub SA, McDonnell JF. Exploring the relationship between cohesion and collective efficacy in rugby teams. J Sport Behav. 2000;23:120-129.

[28] Heuze JP, Bosselut G, Thomas JP. Should the coaches of elite female handball teams focus on collective efficacy or group cohesion? The Sport Psychologist. 2007;21:383-399.

[29] Heuze JP, Raimbault N, Fontayne P. Relationships between cohesion, collective-efficacy and performance in professional basketball teams: An examination of mediating effects. J Sport Sci. 2006;24:5968.

[30] Carron AV, Widmeyer W, Brawley LR. The development of an instrument to assess cohesion in sport teams: The group environment questionnaire. J Sport Psychol. 1985;7:244-266.

[31] Krawczynski M. Spojnosc grupowa a dojrzałosc spoleczna. Studia z psychologii sportu [Group cohesion and social maturity. Studies in sports psychology]. Gdansk: Wydawnictwo Uczelniane AWF; 1995. Polish. 


\section{APPENDIX}

\section{Sense of Team Efficacy Questionnaire}

\section{(Kwestionariusz Poczucia Druzynowej Skutecznosci - KPDS)}

Assess to what extent your team, in the context of approaching game, is certain of their abilities to:

(Remember that your answers are to be a projection of the thinking of your entire team, and not just your impressions. That means: check how confident your team is that it is able to e.g. outplay the opposing team.)

\begin{tabular}{|c|c|c|c|c|c|c|c|c|c|c|c|c|}
\hline & & & & & & & & & & & & \\
\hline 1 & $\begin{array}{l}\text { Get up and regain the lead after } \\
\text { playing poorly }\end{array}$ & 0 & 1 & 2 & 3 & 4 & 5 & 6 & 7 & 8 & 9 & 10 \\
\hline 2 & Outplay the opposing team & 0 & 1 & 2 & 3 & 4 & 5 & 6 & 7 & 8 & 9 & 10 \\
\hline 3 & Keep calm under pressure & 0 & 1 & 2 & 3 & 4 & 5 & 6 & 7 & 8 & 9 & 10 \\
\hline 4 & $\begin{array}{l}\text { Be adequately prepared for this } \\
\text { game }\end{array}$ & 0 & 1 & 2 & 3 & 4 & 5 & 6 & 7 & 8 & 9 & 10 \\
\hline 5 & $\begin{array}{l}\text { Demonstrate a greater resilience } \\
\text { than the opposing team }\end{array}$ & 0 & 1 & 2 & 3 & 4 & 5 & 6 & 7 & 8 & 9 & 10 \\
\hline 6 & Demonstrate physical fitness & 0 & 1 & 2 & 3 & 4 & 5 & 6 & 7 & 8 & 9 & 10 \\
\hline 7 & $\begin{array}{l}\text { Display more ability than the op- } \\
\text { posing team }\end{array}$ & 0 & 1 & 2 & 3 & 4 & 5 & 6 & 7 & 8 & 9 & 10 \\
\hline 8 & Work hard as a team & 0 & 1 & 2 & 3 & 4 & 5 & 6 & 7 & 8 & 9 & 10 \\
\hline 9 & Regain the lead to achieve success & 0 & 1 & 2 & 3 & 4 & 5 & 6 & 7 & 8 & 9 & 10 \\
\hline 10 & Maintain motivation & 0 & 1 & 2 & 3 & 4 & 5 & 6 & 7 & 8 & 9 & 10 \\
\hline 11 & Physically prepare for this game & 0 & 1 & 2 & 3 & 4 & 5 & 6 & 7 & 8 & 9 & 10 \\
\hline 12 & Play as good as possible & 0 & 1 & 2 & 3 & 4 & 5 & 6 & 7 & 8 & 9 & 10 \\
\hline 13 & Maintain a positive attitude & 0 & 1 & 2 & 3 & 4 & 5 & 6 & 7 & 8 & 9 & 10 \\
\hline 14 & Achieve success & 0 & 1 & 2 & 3 & 4 & 5 & 6 & 7 & 8 & 9 & 10 \\
\hline 15 & Cooperate & 0 & 1 & 2 & 3 & 4 & 5 & 6 & 7 & 8 & 9 & 10 \\
\hline 16 & Put in maximum effort & 0 & 1 & 2 & 3 & 4 & 5 & 6 & 7 & 8 & 9 & 10 \\
\hline 17 & Win in this game & 0 & 1 & 2 & 3 & 4 & 5 & 6 & 7 & 8 & 9 & 10 \\
\hline 18 & $\begin{array}{l}\text { Maintain control during the whole } \\
\text { game }\end{array}$ & 0 & 1 & 2 & 3 & 4 & 5 & 6 & 7 & 8 & 9 & 10 \\
\hline 19 & Maintain concentration & 0 & 1 & 2 & 3 & 4 & 5 & 6 & 7 & 8 & 9 & 10 \\
\hline 20 & Mentally prepare for this game & 0 & 1 & 2 & 3 & 4 & 5 & 6 & 7 & 8 & 9 & 10 \\
\hline 21 & $\begin{array}{l}\text { Maintain the commitment to } \\
\text { achieving goals }\end{array}$ & 0 & 1 & 2 & 3 & 4 & 5 & 6 & 7 & 8 & 9 & 10 \\
\hline
\end{tabular}

